\title{
Income Taxes, property Values and Migration
}

\author{
Glazer, Amihai; Kanniainen, Vesa; Poutvaara, Panu
}

Document Version

Final published version

Publication date:

2008

\section{License \\ CC BY-NC-ND}

Citation for published version (APA):

Glazer, A., Kanniainen, V., \& Poutvaara, P. (2008). Income Taxes, property Values and Migration. Centre for Economic and Business Research, Copenhagen Business School.

Link to publication in CBS Research Portal

\section{General rights}

Copyright and moral rights for the publications made accessible in the public portal are retained by the authors and/or other copyright owners and it is a condition of accessing publications that users recognise and abide by the legal requirements associated with these rights.

\section{Take down policy}

If you believe that this document breaches copyright please contact us (research.lib@cbs.dk) providing details, and we will remove access to the work immediately and investigate your claim. 


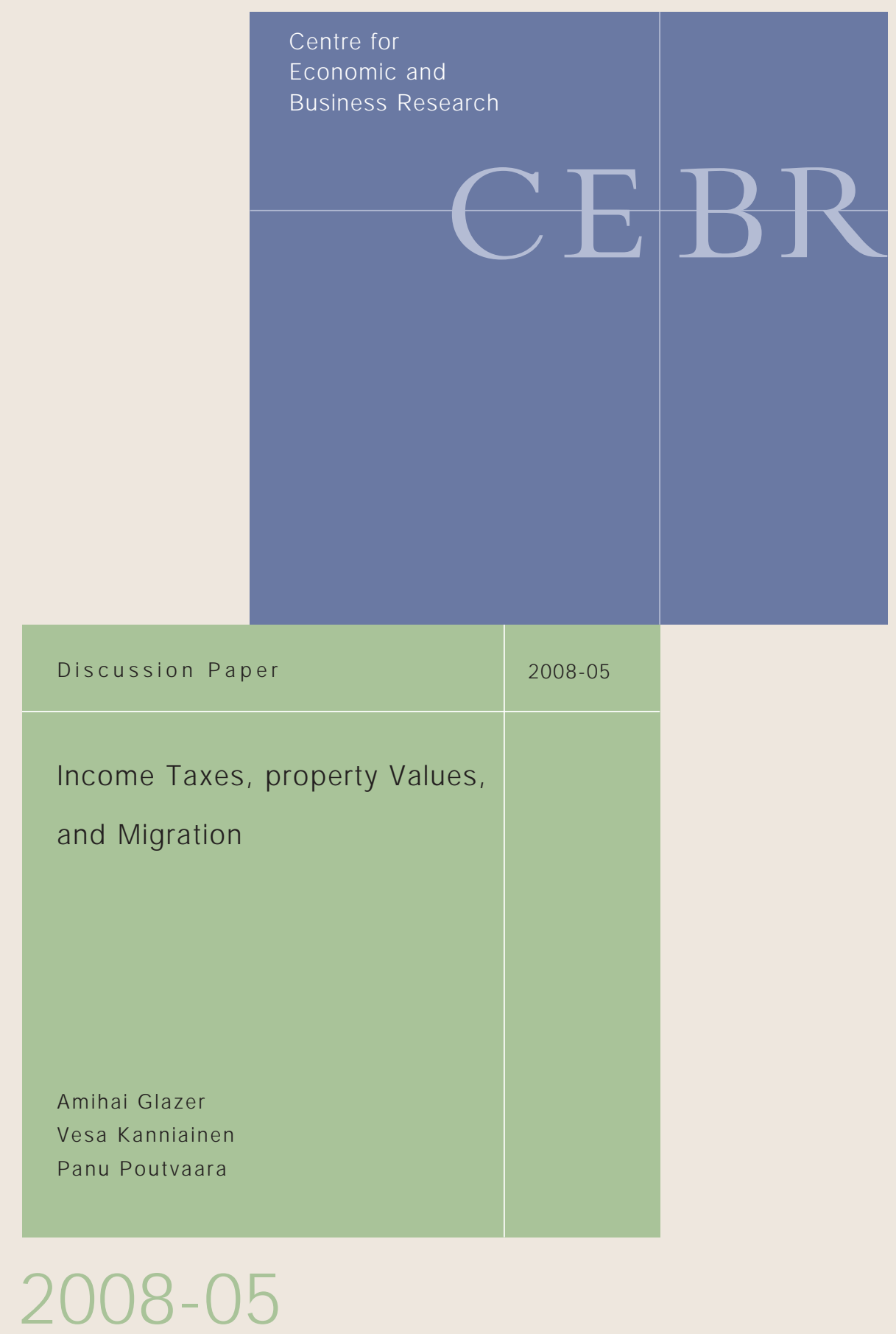




\title{
Income taxes, property values, and migration ${ }^{\text {is }}$
}

\author{
Amihai Glazer $^{a}$, Vesa Kanniainen ${ }^{\text {b,c,*}, \text { Panu Poutvaara }}{ }^{\text {b,c,d }}$ \\ ${ }^{\text {a }}$ Department of Economics, University of California - Irvine, Irvine, California 92697, USA \\ ${ }^{\mathrm{b}}$ Department of Economics, University of Helsinki, Arkadiankatu 7 (P.O. Box 17), 00014, Helsinki, Finland \\ ${ }^{\mathrm{c}}$ HECER, Finland \\ ${ }^{\mathrm{d}}$ CEBR, Copenhagen Business School, Denmark
}

Received 30 November 2006; received in revised form 26 July 2007; accepted 28 July 2007

Available online 7 August 2007

\begin{abstract}
We consider the effects of income redistribution when people can migrate from one country to another, and when land within each country is heterogeneous. Taxes related to income can then affect property values, and can induce migration, which further affects property values. We show that under these conditions a utilitarian government should never equalize after-tax incomes. If migration is impossible, it may even transfer income from the poor to the rich, reducing the rents earned by absentee landlords. The redistributive tax on the rich may be higher or lower when the rich can migrate than when they cannot. A Rawlsian government in the absence of mobility will equalize after-tax incomes. Under mobility, Rawlsian governments cut their taxes if and only if the relative pre-tax income of the poor is sufficiently low.
\end{abstract}

(C) 2007 Elsevier B.V. All rights reserved.

JEL classification: $\mathrm{H} 21 ; \mathrm{H} 7 ; \mathrm{R} 21 ; \mathrm{R} 23$

Keywords: Taxes; Land rents; Property values; Migration; Redistribution

\section{Introduction}

A state or other jurisdiction which imposes high taxes on the rich may induce some residents to move away. Such migration would appear to limit the government's ability to redistribute income or to finance generous social benefits. An extensive literature, starting with Tiebout (1956), identifies conditions under which interjurisdictional competition allows citizens to consume their preferred combination of public services by choosing the jurisdiction in which to live,

\footnotetext{
Earlier versions of this paper were presented at the research seminar at the Department of Economics, University of Helsinki, at the CESifo Area Conference on Public Economics in Munich, and at the World Meeting of the Public Choice Societies in Amsterdam. We thank Heikki Kauppi, Marko Köthenbürger, Mikko Mustonen, Niku Määttänen, Tapio Palokangas and Matthias Wrede for helpful comments on those drafts. We are also indebted to two anonymous referees for valuable comments. Kanniainen and Poutvaara gratefully acknowledge financial support from the Yrjö Jahnsson Foundation and from the Finnish Cultural Foundation.

* Corresponding author. Department of Economics, University of Helsinki, Arkadiankatu 7 (P.O. Box 17), 00014, Helsinki, Finland. Tel.: +358 9 191 28725; fax: +358 919128736 .

E-mail addresses: aglazer@uci.edu (A. Glazer), kanniain@valt.helsinki.fi (V. Kanniainen), panu.poutvaara@helsinki.fi (P. Poutvaara).
} 
with each jurisdiction collecting taxes which just cover the cost of the public goods it provides. Despite this theoretical prediction of no redistribution, governments often redistribute. A race to the bottom is not universal.

Several factors may limit migration: moving is costly; some people prefer one location over another; property values decline in response to higher taxes, thereby reducing the incentives to move. Westhoff (1977), Epple et al. (1984), Goodspeed (1989), Epple and Romer (1991) and Hansen and Kessler (2001) conclude that redistribution and migration stratify communities. The rich end up living in communities imposing low redistributive taxes. This literature assumes that everyone is perfectly mobile and that land is homogeneous. An appropriately defined marginal rate of substitution between housing and other consumption is assumed to vary monotonically across households. Use of such a monotonicity condition on the marginal rate of substitution was first introduced by Ellickson (1971). Under this assumption, households will completely stratify by income across jurisdictions.

We shall examine redistribution financed by an income tax, in the presence of heterogeneous land and differential mobility. In particular, we suppose good locations are scarce: people who want to live near the beach or on top of a mountain with a gorgeous view will find such locations limited. This assumption corresponds to the monocentric city model (see Fujita, 1989). Our model also assumes that the rich, but not the poor, can migrate. This pattern is consistent with behavior in the European Union, where migration is disproportionately large among the highly educated (Docquier and Marfouk, 2004). Like Goodspeed (1989) and Hansen and Kessler (2001), we analyze income taxation. ${ }^{1}$ Unlike those papers, we allow for differential mobility and heterogeneous land within each jurisdiction. ${ }^{2}$ We also assume that governments set taxes on mobile rich people before they migrate, whereas Goodspeed (1989) and Hansen and Kessler (2001) assume that migration decisions are made before tax rates are chosen.

We incorporate the insights of urban economics, namely that taxes are partly capitalized in property values and rents and that land is heterogeneous. These different assumptions modify some conventional results in the public finance literature. A key insight of the literature on tax competition is that mobility of taxpayers reduces the scope for redistribution, and that governments will impose low taxes on persons who may leave the country. This mobility would imply that a utilitarian government aiming to transfer income from the rich to the poor in the absence of migration would redistribute less if the rich can emigrate. We find instead that migration can increase redistribution. We also find that even when taxation does not distort labor supply, a utilitarian government does not fully equalize incomes in a closed economy; it may even engage in regressive redistribution. If migration is possible, a utilitarian government will not impose regressive taxes.

\section{Assumptions}

Consider two jurisdictions. The jurisdictions are ex ante identical and consist of heterogeneous land. For example, the jurisdiction could be viewed as having one hill, or one major city. In the hill interpretation, higher elevations have a better climate or a better view. In the city interpretation, quality declines with distance from the city center. For simplicity, denote land quality by elevation $e$. Elevation increases linearly from 0 to 1 . Each elevation can accommodate a density of one resident. Land is owned by absentee landlords, as in Epple and Romer (1991). Each person within a jurisdiction chooses where to live; the rent at elevation $e$ is $c_{e}$.

There are two types of citizens. In both jurisdictions, the pre-tax income of each rich person is $y^{\mathrm{R}}$; the pre-tax income of each poor person is $y^{\mathrm{P}}$. Initially, each jurisdiction has $n^{\mathrm{R}}$ rich people; migration can change that number. The number of poor residents is fixed at $n^{\mathrm{P}}$; they never migrate. Assume that $n^{\mathrm{P}}+2 n^{\mathrm{R}} \leq 1$, ensuring sufficient space in each jurisdiction for immobile domestic poor and mobile rich from both jurisdictions. All citizens have identical utility functions. An individual's utility defined over consumption of goods $(x)$ and elevation $(e)$ is

$$
U=u(x)+v(e)=\ln (x)+\ln (e) .
$$

Governments can redistribute income between the rich and the poor using group-specific lump-sum taxes. A lumpsum tax on each rich person is denoted by $\tau$. A positive $\tau$ has the government transfer income from the rich to the poor; a negative $\tau$ implies regressive redistribution. Let the number of rich people in jurisdiction $i$ in the equilibrium with

\footnotetext{
${ }^{1}$ Wildasin (1991), Christiansen et al. (1994) and Sinn (1997) explain how migration and possibilities to redistribute income are influenced by relative employment and earnings opportunities. We abstract from this mechanism. We also ignore property taxation, which is analyzed in the presence of homogeneous land by Epple et al. (1984), Epple and Romer (1991) and Wilson (2003), among others.

${ }^{2}$ Also in Goodspeed (1989) and Hansen and Kessler (2001), land is scarce but it is homogeneous.
} 
migration be $n_{i}^{\mathrm{R}}$; then the total tax revenue from them is $n_{i}^{\mathrm{R}} \tau_{i}$. Let each poor person receive a transfer of $t_{i}$, so that aggregate transfers satisfy $n^{\mathrm{P}} t_{i}=n_{i}^{\mathrm{R}} \tau_{i}$. We consider throughout a non-confiscatory tax: the post-tax income of a rich person cannot fall below the post-transfer income of a poor person. This constraint requires that

$$
\tau_{i} \leq \frac{n^{\mathrm{P}}\left(y^{\mathrm{R}}-y^{\mathrm{P}}\right)}{n^{\mathrm{P}}+n_{i}^{\mathrm{R}}} .
$$

\section{Closed economy}

\subsection{Equilibrium of the rental market}

In a closed economy, the population is $n^{\mathrm{R}}+n^{\mathrm{P}}$. The rental market is in equilibrium when land rents are such that no citizen would strictly prefer moving to some other location and no landlord can increase land rent without losing a tenant. As the marginal utility of consumption is diminishing, in equilibrium residences are segregated:

Lemma 1. (i) Independently of their residence, all persons within each income group enjoy the same utility. (ii) If Eq. (2) is satisfied as a strict inequality, the utility of the rich is higher than the utility of the poor and all rich people live in better locations than poor people. (iii) Rents are a continuous and increasing function of elevation.

Proof. (i) To see that utilities are equal within groups, suppose the contrary, that two residents with the same income live in different locations, pay different rents, and enjoy different utility. Then the resident with the less attractive rentlocation combination would gain by offering to pay a marginally higher rent to the landlord of the citizen with the more attractive rent-location combination. (ii) To see that residences are segregated, suppose the opposite: some poor resident lives at a higher elevation than some rich resident. By Eq. (1), the marginal utilities of consumption and of elevation are both positive and diminishing. If the rich and the poor citizen would switch locations, and the rents stay the same, the joint utility of these two residents would increase. Landlords could thus offer at least one location at a higher price for a resident living in the other location. This effect rules out the possibility that the residences were intermingled. (iii) The assertion that rents increase with elevation follows from part (i) of the Lemma. To see that rents are a continuous function, suppose the opposite: at some elevation rents make a discrete jump. Were rents discontinuous, persons living immediately above the discrete jump would find it attractive to move just below it, offering infinitesimally higher rents than those residing there in the tentative equilibrium with a discrete jump.

The rent paid by a rich person in the lowest elevation occupied by the rich is determined by the willingness to pay by the poor for the same location. Consumption by a poor person living at elevation $e$ is $y^{\mathrm{P}}+\frac{n^{\mathrm{R}} \tau}{n^{\mathrm{P}}}-c_{e}$. The willingness to pay by the poor for location $e$ is determined from the condition that rental prices equalize the utilities of all the poor:

$$
\ln \left(y^{\mathrm{P}}+\frac{n^{\mathrm{R}} \tau}{n^{\mathrm{P}}}-c_{e}\right)+\ln (e)=\ln \left(y^{\mathrm{P}}+\frac{n^{\mathrm{R}} \tau}{n^{\mathrm{P}}}\right)+\ln \left(1-n^{\mathrm{R}}-n^{\mathrm{P}}\right) .
$$

Note that the rent at the lowest occupied location, $1-n^{R}-n^{P}$, equals zero. With any positive rent, the poor resident would prefer to move marginally downwards to the adjoining empty slot. This indifference condition for the rental market allows us to determine the rent at the highest location occupied by the poor:

$$
c_{1-n^{\mathrm{R}}}=\frac{y^{\mathrm{P}} n^{\mathrm{P}}+n^{\mathrm{R}} \tau}{\left(1-n^{\mathrm{R}}\right)} .
$$

The rent paid by a rich resident at elevation $e$ (above where the poor live) is ${ }^{3}$

$$
c_{e}=\frac{\left(y^{\mathrm{R}}-\tau\right) e-\left(y^{\mathrm{R}}-\tau\right)\left(1-n^{\mathrm{R}}\right)+y^{\mathrm{P}} n^{\mathrm{P}}+n^{\mathrm{R}} \tau}{e}, \quad 1-n^{\mathrm{R}}<e \leq 1 .
$$

\footnotetext{
${ }^{3}$ This rent can be determined from the indifference condition that the rich must all enjoy the same utility: $\ln \left(y^{\mathrm{R}}-\tau-c_{e}\right)+\ln (e)=$ $\ln \left(y^{R}-\tau-\frac{y^{\mathrm{P}} n^{\mathrm{P}}+n^{\mathrm{R}} \tau}{\left(1-n^{\mathrm{R}}\right)}\right)+\ln \left(1-n^{\mathrm{R}}\right)$.
} 
As $\partial c_{e} / \partial \tau>0$ when $0<e<1$, income redistribution from the rich to the poor also increases the rents the rich pay at all other locations. Note that as long as incomes are not fully equalized (Eq. (2) is satisfied as a strict inequality), Lemma 1 states that the rich pay higher rents. ${ }^{4}$ Those rich living close to the poor consume more than the poor living close to the rich. However, the rich living further up the hill may consume less than some or even all poor persons, and still enjoy higher utility.

\subsection{Optimal tax under a utilitarian government}

By Lemma 1, all residents with the same income enjoy the same utility regardless of their location. Thus, to determine the tax rate that maximizes aggregate welfare of residents, it suffices to derive the effect of the tax on the resident at the lowest location in each income group, and multiply this by the group size. Social welfare is thus ${ }^{5}$

$$
\mathrm{SWF}=n^{\mathrm{R}} U^{\mathrm{R}}+n^{\mathrm{P}} U^{\mathrm{P}} .
$$

The utility of the poor person living at the lowest elevation is

$$
U^{\mathrm{P}}=\ln \left(y^{\mathrm{P}}+\frac{n^{\mathrm{R}} \tau}{n^{\mathrm{P}}}\right)+\ln \left(1-n^{\mathrm{R}}-n^{\mathrm{P}}\right) .
$$

The utility of the rich person living just above a poor person is

$$
U^{\mathrm{R}}=\ln \left(y^{\mathrm{R}}-\tau-\frac{y^{\mathrm{P}} n^{\mathrm{P}}+n^{\mathrm{R}} \tau}{\left(1-n^{\mathrm{R}}\right)}\right)+\ln \left(1-n^{\mathrm{R}}\right) .
$$

Thus,

$$
\mathrm{SWF}=n^{\mathrm{R}} \ln \left(y^{\mathrm{R}}\left(1-n^{\mathrm{R}}\right)-\tau-y^{\mathrm{P}} n^{\mathrm{P}}\right)+n^{\mathrm{P}} \ln \left(\left(y^{\mathrm{P}}+\frac{n^{\mathrm{R}} \tau}{n^{\mathrm{P}}}\right)\left(1-n^{\mathrm{R}}-n^{\mathrm{P}}\right)\right) .
$$

We can now derive:

Proposition 1. A utilitarian government may impose either a positive or a negative tax on the rich.

Proof. Differentiating Eq. (6) with respect to $\tau$, setting the first-order condition equal to zero ${ }^{6}$ and solving for $\tau$ yields the optimal tax for a utilitarian government:

$$
\tau=\frac{y^{\mathrm{R}}}{n^{\mathrm{R}} / n^{\mathrm{P}}+1}\left(\left(1-n^{\mathrm{R}}\right)-\frac{y^{\mathrm{P}}}{y^{\mathrm{R}}}\left(1+n^{\mathrm{P}}\right)\right) .
$$

From Eq. (7), $\tau>0$ if and only if $y^{\mathrm{P}} / y^{\mathrm{R}}<\frac{1-n^{\mathrm{R}}}{1+n^{\mathrm{P}}}$. The welfare-maximizing $\tau$ is negative if and only if $y^{\mathrm{P}} / y^{\mathrm{R}}>\frac{1-n^{\mathrm{R}}}{1+n^{\mathrm{P}}}$.

From Eq. (7), we see that the benefits of redistributing income from the rich to the poor declines with the relative income of the poor, $y^{\mathrm{P}} / y^{\mathrm{R}}$. When this ratio reaches a critical value of $\left(1-n^{\mathrm{R}}\right) /\left(1+n^{\mathrm{P}}\right)$, the government chooses a tax of zero; further increases in $y^{\mathrm{P}} / y^{\mathrm{R}}$ result in a negative tax on the rich. Furthermore, this critical value increases with $n^{\mathrm{P}}$ and declines with $n^{\mathrm{R}}$. This relation implies that with given relative incomes, an increase in the size of the poor population makes progressive income redistribution more attractive; an increase in the size of the rich population

\footnotetext{
${ }^{4}$ The rent gradient of the poor can be found by totally differentiating Eq. (3) with respect to $e$ and $c_{e}$, and the rent gradient of the rich can be found by totally differentiating Eq. (5) with respect to $e$ and $c_{e}$. From these, the rent gradients of the poor and of the rich are both upward-sloping and concave curves in a coordinate system with $e$ on the horizontal axis, and $c_{e}$ on the vertical axis. Furthermore, the rent gradient of the rich is steeper than that of the poor at the point where the rent gradients cross each other. They intersect right at the point where the location of the highest poor meets the location of the lowest rich. The formal proof is available from the authors upon request.

${ }^{5}$ Following Epple and Romer (1991) and Hansen and Kessler (2001), we consider absentee landlords, whose income does not enter into social welfare.

${ }^{6}$ The second-order condition verifies that the first-order condition gives the tax rate which maximizes social welfare.
} 
makes a regressive tax more attractive. For example, let $y^{\mathrm{R}}=1, n^{\mathrm{P}}=0.4$, and $n^{\mathrm{R}}=0.3$. Then the condition for a positive $\tau$ is that $y^{\mathrm{P}}<1 / 2$. The condition that $\tau$ in Eq. (7) fulfills Eq. (2) is satisfied. We find an even stronger result:

Proposition 2. A utilitarian government should never fully equalize incomes.

Proof. We show that the tax rate chosen by a utilitarian government is less than $\frac{n^{\mathrm{P}}\left(y^{\mathrm{R}}-y^{\mathrm{P}}\right)}{n^{\mathrm{R}}+n^{\mathrm{P}}}$ in Eq. (2). This inequality holds when

$$
\frac{y^{\mathrm{R}}}{n^{\mathrm{R}} / n^{\mathrm{P}}+1}\left(\left(1-n^{\mathrm{R}}\right)-\frac{y^{\mathrm{P}}}{y^{\mathrm{R}}}\left(1+n^{\mathrm{P}}\right)\right)<\frac{n^{\mathrm{P}}\left(y^{\mathrm{R}}-y^{\mathrm{P}}\right)}{n^{\mathrm{R}}+n^{\mathrm{P}}},
$$

reducing to the condition $n^{\mathrm{P}} y^{\mathrm{P}}+n^{\mathrm{R}} y^{\mathrm{R}}>0$, which always holds.

To summarize, a utilitarian government should not fully equalize the incomes of the rich and the poor, and may even transfer income from the poor to the rich. This surprising result arises from the presence of heterogeneous land. It would not arise if, instead, land is homogeneous and households derive utility from lot size $s$, with all households having identical utility functions $U=\ln (x)+\ln (s){ }^{7}$ The result on regressive taxation relates to the limitation on the government's tax instrument. In the presence of heterogeneous land, group-specific lump-sum taxes do not suffice to equalize consumption. Instead, the rich living at the top of the hill may have higher marginal utility of consumption than many or even all of the poor. ${ }^{8}$ Furthermore, by transferring income from the poor, the government reduces the rents the poor will pay. The lower rents paid by the poor in turn reduce the rents paid by the rich. Thus, by transferring income from the poor to the rich, the government reduces rents and thus increases consumption. If land is homogeneous and the rich and the poor differ in the amount of land they rent, as in Epple and Romer (1991), then in equilibrium the rich would consume more land and other goods. The government would then avoid redistributing from the poor to the rich.

\subsection{Optimal tax under a Rawlsian government}

By Lemma 1, a Rawlsian government maximizes the income of the poor. As all the poor have the same income, the problem of a Rawlsian government is equivalent to setting a tax which maximizes the income of the poor person living at the lowest location. As the rent paid at the lowest location is zero, this is equivalent to maximizing the lump-sum transfer to the poor. Condition (2) would be satisfied as an equality, and the government would choose $\tau=\frac{n^{\mathrm{P}}\left(y^{\mathrm{R}}-y^{\mathrm{P}}\right)}{n^{\mathrm{P}}+n^{\mathrm{R}}}$. This tax would equalize all incomes, after taxes and transfers.

\section{Open economy}

\subsection{Migration and rental markets}

We now turn our attention to migration between countries. Assume two countries, $a$ and $b$, with $n^{\mathrm{R}}$ rich people initially living in each country. The rich can migrate at zero cost, and exhibit no home country preference. Each jurisdiction has $n^{\mathrm{P}}>0$ poor residents, who do not migrate. Each person pays taxes in the country in which he lives. Then a tax on the rich creates an incentive to emigrate. We thus make the lowest locations occupied in each country endogenous. As we are concerned with tax competition, we suppose that governments simultaneously choose their tax rates; people observe the tax rates when deciding whether to migrate. We continue to assume that taxes satisfy Eq. (2). As a result, in equilibrium, the rich live above the poor, consistent with Lemma 1.

For any given tax, the equilibrium when people can migrate is determined by a system of six simultaneous equations. These equations represent per capita transfers to the poor, the rents paid by the rich at the lowest elevation

\footnotetext{
${ }^{7}$ Proof is available upon request. An interesting parallel is to Hansen and Kessler (2001), who find that a large jurisdiction can maintain a high tax because emigration of the (moderately) rich to the tax haven is limited by high property values there. Also in our paper, scarcity of land limits tax competition. We assume, however, that because land is heterogeneous, scarcity applies inside each jurisdiction. Hansen and Kessler (2001) assume that jurisdictions differ in their size, but that within each jurisdiction land is homogeneous.

${ }^{8}$ The government could equalize marginal utilities of non-location consumption only if it could arbitrarily allocate citizens to different elevations and abolish the rental market.
} 
that they occupy in the two countries, the population identity, and the arbitrage condition that the utility of the rich is the same in the two jurisdictions.

The per-capita transfer to the poor in country $i$ is

$$
t_{i}=\frac{n_{i}^{\mathrm{R}} \tau_{i}}{n^{\mathrm{P}}}
$$

The arbitrage condition in the rental market gives the rent paid by the poor in country $i$ in the highest location that they occupy

$$
\ln \left(y^{\mathrm{P}}+\frac{n_{i}^{\mathrm{R}} \tau_{i}}{n^{\mathrm{P}}}-c_{1-n_{i}^{\mathrm{R}}}\right)+\ln \left(1-n_{i}^{\mathrm{R}}\right)=\ln \left(y^{\mathrm{P}}+\frac{n_{i}^{\mathrm{R}} \tau_{i}}{n^{\mathrm{P}}}\right)+\ln \left(1-n_{i}^{\mathrm{R}}-n^{\mathrm{P}}\right) .
$$

Eq. (9) yields

$$
c_{1-n_{i}^{\mathrm{R}}}=\frac{y^{\mathrm{P}} n^{\mathrm{P}}+n_{i}^{\mathrm{R}} \tau_{i}}{\left(1-n_{i}^{\mathrm{R}}\right)} .
$$

The population identity states that the sum of post-migration rich populations equals the sum of initial rich populations:

$$
n_{a}^{\mathrm{R}}+n_{b}^{\mathrm{R}}=2 n^{\mathrm{R}} .
$$

The arbitrage condition imposed by migration of the rich across the two jurisdictions is that

$$
\ln \left(y^{\mathrm{R}}-\tau_{a}-c_{1-n_{a}^{\mathrm{R}}}\right)+\ln \left(1-n_{a}^{R}\right)=\ln \left(y^{\mathrm{R}}-\tau_{b}-c_{1-n_{b}^{\mathrm{R}}}\right)+\ln \left(1-n_{b}^{R}\right) .
$$

Substituting $c_{1-n_{a}^{R}}$ and $c_{1-n_{b}^{R}}$ from Eq. (10), and inserting Eq. (11), we can solve from the migration arbitrage condition the post-migration rich population in country $a$ :

$$
n_{a}^{\mathrm{R}}=\frac{\left(y^{\mathrm{R}}-\tau_{a}\right)-\left(y^{\mathrm{R}}-\tau_{b}\right)\left(1-2 n^{\mathrm{R}}\right)+2 n^{\mathrm{R}} \tau_{b}}{2 y^{\mathrm{R}}} .
$$

Similarly, in the post-migration equilibrium the number of rich persons living in country $b$ is

$$
n_{b}^{\mathrm{R}}=\frac{\left(y^{\mathrm{R}}-\tau_{b}\right)-\left(y^{\mathrm{R}}-\tau_{a}\right)\left(1-2 n^{\mathrm{R}}\right)+2 n^{\mathrm{R}} \tau_{a}}{2 y^{\mathrm{R}}} .
$$

Note that Eqs. (13) and (14) are independent of the number of the poor. Though migration depends on the share of tax revenue transferred to the poor, it does not depend on how many poor receive the transfer.

\subsection{Utilitarian government policies}

Each government maximizes the utility of citizens initially living in the country. ${ }^{9}$ Social welfare in country $a$ is

$$
\mathrm{SWF}_{a}^{u}=n^{\mathrm{P}} \ln \left(y^{\mathrm{P}}+t_{a}\right)+n^{\mathrm{P}} \ln \left(1-n^{\mathrm{P}}-n_{a}^{\mathrm{R}}\right)+n^{\mathrm{R}} \ln \left(y^{\mathrm{R}}-\tau_{a}-c_{1-n_{a}^{\mathrm{R}}}\right)+n^{\mathrm{R}} \ln \left(1-n_{a}^{\mathrm{R}}\right) .
$$

\footnotetext{
${ }^{9}$ This assumption is needed because if the government maximizes the sum of the utilities of citizens living in the country after migration, and were utility negative, then each government would want a zero population. Furthermore, maximizing the utility of initial citizens would result from probabilistic voting taking place before migration decisions. Note that the utility of the rich is the same in the two countries (Eq. (12)).
} 
In choosing the tax, a government must pay attention to its budget constraint, to the effects of a tax on land rents, and to migration responses that equalize the utility of the rich between the two jurisdictions. Inserting Eqs. (8), (10) and (13) into (15) and differentiating with respect to $\tau_{a}$ yields

$$
\begin{aligned}
\frac{\partial \mathrm{SWF}_{a}^{u}}{\partial \tau_{a}}= & \frac{n^{\mathrm{P}}\left(-2 \tau_{a}+\tau_{b}+2 n^{\mathrm{R}} y^{\mathrm{R}}\right)}{2 y^{\mathrm{R}} n^{\mathrm{P}} y^{\mathrm{P}}-\tau_{a}^{2}+\tau_{a} \tau_{b}+2 \tau_{a} n^{\mathrm{R}} y^{\mathrm{R}}}+\frac{n^{\mathrm{P}}}{2 y^{\mathrm{R}}+\tau_{a}-\tau_{b}-2 n^{\mathrm{R}} y^{\mathrm{R}}-2 y^{\mathrm{R}} n^{\mathrm{P}}} \\
& +\frac{-n^{\mathrm{R}}}{2 y^{\mathrm{R}}-\tau_{a}-\tau_{b}-2 n^{\mathrm{R}} y^{\mathrm{R}}-2 y^{\mathrm{P}} n^{\mathrm{P}}} .
\end{aligned}
$$

When condition (2) does not bind, $\frac{\partial^{2} \mathrm{SWF}_{a}^{u}}{\partial \tau_{a}^{2}}<0$ at $\tau_{b}=\tau_{a}$. Thus, a symmetric Nash equilibrium exists. We focus on it, as is common in the literature on fiscal federalism which considers ex ante identical jurisdictions and migrants of the same type; see Wildasin (1991), Wildasin and Wilson (1996), and Zodrow and Mieszkowski (1986). Thus, we can simplify by using the symmetry property that $\tau_{a}=\tau_{b}=\tau$ :

$$
\begin{aligned}
& \frac{n^{\mathrm{P}}\left(-\tau+2 n^{\mathrm{R}} y^{\mathrm{R}}\right)}{2 y^{\mathrm{R}} n^{\mathrm{P}} y^{\mathrm{P}}+2 \tau n^{\mathrm{R}} y^{\mathrm{R}}}+\frac{n^{\mathrm{P}}}{2 y^{\mathrm{R}}-2 n^{\mathrm{R}} y^{\mathrm{R}}-2 y^{\mathrm{R}} n^{\mathrm{P}}} \\
& -\frac{n^{\mathrm{R}}}{\left(2 y^{\mathrm{R}}-2 \tau-2 n^{\mathrm{R}} y^{\mathrm{R}}\right)-2 y^{\mathrm{P}} n^{\mathrm{P}}}=0 .
\end{aligned}
$$

Our main result is:

Proposition 3. The possibility of migration has ambiguous effects on taxes set by utilitarian governments.

Proof. We give an example where the equilibrium tax is higher under migration than without, and an example where the equilibrium tax is lower. If $n^{\mathrm{P}}=n^{\mathrm{R}}=y^{\mathrm{P}}=0.1$ and $y^{\mathrm{R}}=1$, the optimal tax in a closed economy (with migration not possible) is 0.395 ; the optimal tax under tax competition (with migration possible) is 0.195 . If $n^{\mathrm{P}}=n^{\mathrm{R}}=0.1, y^{\mathrm{P}}=0.5$ and $y^{\mathrm{R}}=1$, the optimal tax in a closed economy is 0.175 , and the optimal tax under tax competition is 0.183 .

It is no surprise that migration (or tax competition) can lead to lower taxes: the ability of the rich to migrate constrains the government's ability to tax them. But the opposite result appears novel and surprising. Tax competition can increase tax rates because of the effects that appear in the rental market for land. Emigration of rich taxpayers reduces competition for desirable locations and so reduces rents. The reduced rents benefit the poor, either because they pay lower rents, or because they live in better locations. Immigration of the rich, on the other hand, generates two effects for the receiving country. Rich migrants generate more tax revenue. But they also bid up rents. When the rent effect dominates, a utilitarian government would prefer to induce some rich people to leave the country. When symmetric countries in a Nash equilibrium choose identical tax rates, no one migrates. A government, however, may impose a higher tax than in a closed economy. Thus, the ability of the rich to avoid taxes by migrating may hurt them by inducing both countries to impose higher taxes.

\subsection{Rawlsian government policies}

A Rawlsian government chooses the tax to maximize the welfare of the poor:

$$
\mathrm{SWF}_{a}^{\mathrm{R}}=n^{\mathrm{P}} \ln \left(y^{\mathrm{P}}+t_{a}\right)+n^{\mathrm{P}} \ln \left(1-n^{\mathrm{P}}-n_{a}^{\mathrm{R}}\right) .
$$

Inserting Eqs. (8) and (13) into (18) and differentiating with respect to $\tau_{a}$ yields

$$
\frac{\partial \mathrm{SWF}_{a}^{\mathrm{R}}}{\partial \tau_{a}}=\frac{n^{\mathrm{P}}\left(-2 \tau_{a}+\tau_{b}+2 n^{\mathrm{R}} y^{\mathrm{R}}\right)}{2 y^{\mathrm{R}} n^{\mathrm{P}} y^{\mathrm{P}}-\tau_{a}^{2}+\tau_{a} \tau_{b}+2 \tau_{a} n^{\mathrm{R}} y^{\mathrm{R}}}+\frac{n^{\mathrm{P}}}{2 y^{\mathrm{R}}+\tau_{a}-\tau_{b}-2 n^{\mathrm{R}} y^{\mathrm{R}}-2 y^{\mathrm{R}} n^{\mathrm{P}}} .
$$


We focus on symmetric equilibria. Note that $\frac{\partial^{2} \mathrm{SWF}_{a}^{\mathrm{R}}}{\partial \tau_{a}^{2}}<0$ at $\tau_{b}=\tau_{a}$. Thus, a symmetric Nash equilibrium exists. We can simplify by using the symmetry property that $\tau_{a}=\tau_{b}=\tau$ :

$$
\frac{\partial \mathrm{SWF}_{a}^{\mathrm{R}}}{\partial \tau_{a}}=\frac{n^{\mathrm{P}}\left(-\tau+2 n^{\mathrm{R}} y^{\mathrm{R}}\right)}{2 y^{\mathrm{R}} n^{\mathrm{P}} y^{\mathrm{P}}+2 \tau n^{\mathrm{R}} y^{\mathrm{R}}}+\frac{n^{\mathrm{P}}}{2 y^{\mathrm{R}}-2 n^{\mathrm{R}} y^{\mathrm{R}}-2 y^{\mathrm{R}} n^{\mathrm{P}}} .
$$

If Eq. (2) does not bind, we can set the right-hand side of Eq. (19) equal to zero and solve for $\tau$ :

$$
\tau^{\mathrm{R}}=\frac{n^{\mathrm{P}} y^{\mathrm{P}}+2 n^{\mathrm{R}} y^{\mathrm{R}}\left(1-n^{\mathrm{R}}-n^{\mathrm{P}}\right)}{\left(1-2 n^{\mathrm{R}}-n^{\mathrm{P}}\right)} .
$$

We can now show:

Proposition 4. A Rawlsian government chooses the same tax rate when the rich can migrate as when the rich cannot if and only if

$$
\frac{y^{\mathrm{P}}}{y^{\mathrm{R}}} \geq \frac{n^{\mathrm{P}}\left(1-2 n^{\mathrm{R}}-n^{\mathrm{P}}\right)-2 n^{\mathrm{R}}\left(1-n^{\mathrm{R}}-n^{\mathrm{P}}\right)\left(n^{\mathrm{R}}+n^{\mathrm{P}}\right)}{n^{\mathrm{P}}\left(1-n^{\mathrm{R}}\right)} .
$$

If this condition is violated, a Rawlsian government chooses a lower tax rate on the rich when they can migrate than when they cannot.

Proof. Section 3.3 reported that a Rawlsian government would choose without mobility of the rich $\tau=\frac{n^{\mathrm{P}}\left(y^{\mathrm{R}}-y^{\mathrm{P}}\right)}{n^{\mathrm{P}}+n^{\mathrm{R}}}$. A Rawlsian government chooses a lower tax rate when the rich can migrate if $\tau^{\mathrm{R}}$ from Eq. (20) is lower than $\tau=\frac{n^{\mathrm{P}}\left(y^{\mathrm{R}}-y^{\mathrm{P}}\right)}{n^{\mathrm{P}}+n^{\mathrm{R}}}$.

Interestingly, the possibility of migration under a Rawlsian government does not induce lower taxes on the rich if the relative income of the poor is sufficiently high. If, however, the relative income of the poor is sufficiently low, the taxes imposed on the rich by a Rawlsian government would be lower when the rich can migrate than when they cannot. The intuition for this result is the following. Emigration of the rich has two effects on the welfare of the poor in the source country. First, emigration reduces the tax revenue available for income redistribution. Second, emigration vacates better lots for the poor to move up the hill.

The smaller the income difference between the rich and the poor, the smaller the maximum tax on the rich, as given by Eq. (2), the smaller the government's revenue gain from immigrants, and so the less the government's gain from lowering taxes which would attract rich persons into the country. With a sufficiently small income difference, the government chooses the maximum tax allowed by Eq. (2). Note, however, that even if the condition (2) did not bind, a Rawlsian government would not choose a higher tax rate. If both jurisdictions would levy a higher tax on the initially rich people, these would become poorer than the poor, and thus the Rawlsian government should reduce their taxes to maximize the utility of the worst-off person.

\section{Conclusion}

The urban economics view of taxation and migration complements the standard public finance view of taxation with mobility. The fall in property values reduces the incentive of the rich to migrate, thereby allowing for more redistributive taxation than is predicted by standard models in public finance. Our paper established that if land is heterogeneous and if the rich and the poor have identical utility functions with diminishing marginal utility of both income and location, then utilitarian and Rawlsian governments tax the rich to finance transfers to the poor. The redistribution occurs even in the absence of mobility costs or complementarities between the rich and the poor. Our finding relates to, yet differs from, the contributions by Goodspeed (1989), Epple and Romer (1991), Hansen and Kessler (2001) and subsequent work in that tradition. There, tax rates are decided by majority voting after migration, and land is homogeneous. In our paper, utilitarian or Rawlsian governments decide on taxes on the rich before these migrate, and land is heterogeneous.

Furthermore, the presence of heterogeneous land implies that initially identical consumers end up with different levels of non-housing consumption. We find that when rents are endogenous, a utilitarian government in a closed 
economy may redistribute from the poor to the rich. The intuition for why such redistribution is feasible is that taxes on the poor reduce rents that both the poor and the rich pay. The resultant utility gains may exceed the decline in consumption by the poor. This result would not arise with homogeneous land.

When the rich can migrate, and government disregards the welfare of landlords, a utilitarian government may impose a higher tax with migration than when the rich cannot migrate. The result can arise because a tax which induces emigration of the rich reduces demand for desirable locations, allowing the poor to enjoy better locations. The increased number of rich people in the other country can also generate an externality, reducing the welfare of the poor in that country. Tax competition can then lead both countries to tax the rich more heavily when the rich can migrate than when they cannot. Though such a strong result does not always apply, it suggests that accounting for responses in the housing market can overturn common views on the effects of migration on income redistribution.

We also find that when migration is possible, a Rawlsian government aims to equalize after-tax incomes only if the income of the poor is sufficiently high relative to the income of the rich. If income differences between the poor and the rich are above a threshold level, Rawlsian governments compete for the mobile rich by taxing them lightly.

\section{References}

Christiansen, Vidar, Hagen, Kåre P., Sandmo, Agnar, 1994. The scope for taxation and public expenditures in an open economy. Scandinavian Journal of Economics 96 (3), 289-309.

Docquier, Frédéric, Marfouk, Abdeslam, 2004. Measuring the international mobility of skilled workers (1990-2000): release 1.0. World Bank Policy Research Working Paper, vol. 3381.

Ellickson, Bryan, 1971. Jurisdictional fragmentation and residential choice. American Economic Review 61 (2), $334-339$.

Epple, Dennis, Romer, Thomas, 1991. Mobility and redistribution. Journal of Political Economy 99, 828-858.

Epple, Dennis, Filimon, R., Romer, Thomas, 1984. Equilibrium among local jurisdictions: towards an integrated treatment of voting and residential choice. Journal of Public Economics 24, 281-308.

Fujita, Masahisa, 1989. Urban Economic Theory. Cambridge University Press, Cambridge, England.

Goodspeed, Timothy J., 1989. A re-examination of the use of ability to pay taxes by local governments. Journal of Public Economics 38, 319-342.

Hansen, Nico A., Kessler, Anke S., 2001. The political geography of tax h(e)avens and tax hells. American Economic Review 91, 1103-1115.

Sinn, Hans W., 1997. The selection principle and market failure in systems competition. Journal of Public Economics 66, $247-274$.

Tiebout, Charles M., 1956. A pure theory of local expenditures. Journal of Political Economy 64, 416-424.

Westhoff, Frank H., 1977. Existence of equilibria in economies with a local public good. Journal of Economic Theory 14, 84-112.

Wildasin, David E., 1991. Income redistribution in a common labor market. American Economic Review 81, 757-774.

Wildasin, David E., Wilson, John D., 1996. Imperfect mobility and local government behaviour in an overlapping-generations model. Journal of Public Economics 60, 177-198.

Wilson, John D., 2003. The property tax: competing views and a hybrid theory. In: Cnossen, Sijbren, Sinn, Hans Werner (Eds.), Public Finance and Public Policy in the New Century. MIT Press, Cambridge.

Zodrow, George R., Mieszkowski, Peter, 1986. Pigou, Tiebout, property taxation, and the underprovision of local public goods. Journal of Urban Economics 19, 356-370 